\title{
Vivências e reflexões ante a obra sociedade do cansaço
}

\author{
Experiences and reflections on the work Society of Tiredness \\ Experiencias y reflexiones ante la obra Sociedad del de cansancio
}

Rafael Cerqueira Fornasier

ORCID: https://orcid.org/0000-0001-5982-6454

Universidade Católica do Salvador, Brasil

E-mail: rafael.fornasier@ucsal.br

Elaine Pedreira Rabinovich

ORCID: https://orcid.org/0000-0002-3048-6609

Universidade Católica do Salvador, Brasil

E-mail: elaine.rabinovich@pro.ucsal.br

Giovana Rossi Figueirôa

ORCID: https://orcid.org/0000-0001-5551-6686

Universidade Católica do Salvador, Brasil

E-mail: giovana.figueiroa@pro.ucsal.br

Sandra Ribeiro Bastos Silveira

ORCID: https://orcid.org/0000-0001-9823-9172

Universidade Católica do Salvador, Brasil

E-mail: sandra.silveira@ucsal.edu.br

Gilmara Rodrigues Correia

ORCID: https://orcid.org/0000-0003-3206-1345

Santa Casa de Misericórdia da Bahia, Brasil

E-mail: gilmara.correia@ucsal.edu.br

Jeane Alice da Silva Leite Lordelo

ORCID: https://orcid.org/0000-0002-4834-203X

Colégio Estadual Alberto Santos Dumont, Brasil

E-mail: jeane.lordelo@ucsal.edu.br

Flávia Guimarães Simões Santos

ORCID: https://orcid.org/0000-0002-0510-412X

Centro de Referência Estadual de Atenção à Saúde do Idoso., Brasil

E-mail: flaviag.santos@ucsal.edu.br

Ana Cristina de Jesus Santana

ORCID: https://orcid.org/0000-0003-3608-7155

Psicóloga Clínica, Brasil

E-mail: anacristina.santos@ucsal.edu.br

\section{Resumo}

O objetivo deste artigo foi mostrar como a obra Sociedade do Cansaço (2017) de Byung-Chul Han se refletiu e foi refletida pelos mestrandos, doutorandos e dois professores, durante o momento da pandemia, conduzindo a uma discussão ampla e aprofundada da temática família. Por meio de comentários, os participantes, professores e alunos da disciplina Família e Subjetividade do Programa de Pós-Graduação em Família na Sociedade Contemporânea da Universidade Católica do Salvador-BA, no primeiro semestre de 2021, buscaram estabelecer conexões e significados entre o conteúdo da obra e suas próprias experiências em seus contextos sócio-históricos-profissionais específicos. Como Han advoga a existência de uma comunidade que não precisa de pertença nem de parentesco, finalizou-se com uma discussão sobre o significado de família, entendida no contexto das ideias filosóficas, sociológicas e psicológicas. Palavras-chave: Sociedade do cansaço; Byung-Chul Han; Reflexões; Relações familiares.

\begin{abstract}
The purpose of this article was to show how Byung-Chul Han's Tiredness Society (2017) was reflected by the master and doctoral students and two teachers, during the time of the pandemic, leading to a broad and in-depth discussion on the family theme. Through comments, the participants, teachers, and students of the academic discipline Family and Subjectivity of the Graduate Program in Family in Contemporary Society at the Catholic University of Salvador-BA, in the first semester of 2021, sought to establish connections and meanings between the content of the work and their own experiences in their specific socio-historical-professional contexts. As Han advocates the existence of a community that doesn't need belonging or kinship, it ended with a discussion of the meaning of family, understood in the context of philosophical, sociological, and psychological ideas.
\end{abstract}

Keywords: Tiredness society; Byung-Chul Han; Reflections; Family relationship. 


\begin{abstract}
Resumen
El propósito de este artículo fue mostrar cómo el trabajo Sociedad do Cansancio (2017) de Byung-Chul Han se reflejó y fue reflejado por estudiantes de maestría, de doctorado y dos profesores, durante la época de la pandemia, dando lugar a un debate amplio y en profundidad del tema familia. A través de comentarios, los participantes, docentes y estudiantes de la disciplina Familia y Subjetividad del Programa de Posgrado en Familia en la Sociedad Contemporánea de la Universidad Católica de Salvador-BA, en el primer semestre de 2021, buscaron establecer conexiones y significados entre el contenido del texto y sus propias experiencias en sus contextos socio-históricoprofesionales específicos. Como Han aboga por la existencia de una comunidad que no necesita pertenencia ni parentesco, el debate fue finalizado con una discusión sobre el significado de familia, entendida en el contexto de las ideas filosóficas, sociológicas y psicológicas.
\end{abstract}

Palabras clave: Sociedad del cansancio; Byung-Chul Han; Reflexiones; Relaciones familiares.

\title{
1. Introduçãa
}

Este artigo enfocou as vivências e reflexões dos professores e alunos da disciplina Família e Subjetividade do Programa de Pós-Graduação em Família na Sociedade Contemporânea da Universidade Católica do Salvador-BA, no primeiro semestre de 2021, suscitadas pela obra Sociedade do Cansaço do filósofo Byung-Chul Han, em um momento histórico específico causado pela pandemia decorrente da COVID-19. Por meio de comentários, os participantes buscaram estabelecer conexões e significados entre o conteúdo da obra e suas próprias experiências em seus contextos sócio-históricos-profissionais específicos. Deste modo, o objetivo deste artigo é mostrar como a referida obra se refletiu e foi refletida pelos mestrandos e doutorandos durante o momento da pandemia, o que acabou conduzindo a uma discussão ampla e aprofundada da temática da família.

\section{Metodologia}

Trata-se de um trabalho de aporte qualitativo que consistiu na transcrição dos relatos oferecidos pelos alunos, regulares e especiais, e professores durante uma disciplina ministrada no Programa de Pós-graduação em Família na Sociedade Contemporânea da Universidade Católica do Salvador-BA, no primeiro semestre de 2021. O conteúdo de tais relatos perpassa pelas vivências e reflexões dos alunos e professores durante a pandemia, associando-as ao texto oferecido como objeto de leitura da aula, A sociedade do cansaço de Byung-Chul Han, e relacionando-o com outras obras do mesmo autor e de autores familiares a este ou que elaboraram reflexões convergentes com as do autor em questão. Nos procedimentos, assume-se, por um lado, a revisão de literatura, e, por outro, a pesquisa documental, por se valer de exploração de fonte documental que, neste caso, se refere à gravação de uma aula (Gil, 2008).

A aula foi inteiramente gravada por meio do aplicativo Google Meet. Em seguida, foi feita uma transcrição na íntegra de todo o conteúdo da mesma. O resultado da transcrição foi lido e relido pelos participantes da disciplina, autores do presente artigo, proporcionando aos sujeitos das falas uma ampla revisão e precisão dos relatos em confronto com a literatura. Por fim, os professores realizaram uma revisão global do texto em função do objetivo geral do presente artigo, chegando aos seguintes resultados e discussão.

\section{Resultados e Discussão}

Elaine - O Livro Sociedade do Cansaço de Byung-Chul Han (2017) é o primeiro de uma série do mesmo autor publicada pela Editora Vozes. O texto do Han trata dos processos de subjetivação na contemporaneidade, donde ter sido objeto desta nossa aula. Sul-coreano, realizou seus estudos na Alemanha, onde é professor em Berlim. Sociedade do cansaço foi originariamente escrito em alemão e datado de 2010.

Para Han, na Sociedade do Cansaço (2017), o homem como um todo se transforma numa máquina do desempenho, que deve funcionar livre de perturbações e maximizar o seu desempenho. Isso ele descreve como o excesso de positividade. 
Podemos parar um pouco para refletir sobre a vida que estamos levando, sempre mediada pelas "maquininhas". Como fica a questão do desempenho?

Rafael - Este é mais um elemento que vem a se acrescentar a esse movimento que o Han já tinha identificado lá atrás, um movimento no qual estava inserida toda a mediação da Tecnologia da Informação e Comunicação, para utilizar essa expressão que engloba tudo, tudo que é software e hardware.

A Tecnologia da Informação e Comunicação vem mediando bastante as nossas relações profissionais, familiares, de amizade, de conhecimento, na área da educação, mas agora, com a pandemia, isso foi maximizado, ou seja, chegou a um grau elevadíssimo de utilização e, como alguns de nós professores relatávamos no final do ano passado, - e penso que quem é aqui professor também sentiu isso - nós nos sentimos muito mais cansados no final do ano passado por que estávamos dando aula online. Refiro-me àqueles que dão aula no ensino superior privado que se manteve, por que o público parou na sua grande maioria. Assim, nós nos sentimos muito cansados no final do ano, porque é como diziam alguns profissionais, trabalhar em casa parecia e parece que temos que estar disponíveis 24 horas. Os alunos mandam mensagens pelo WhatsApp, pelo Google sala de aula, mandam pelo e-mail, por SMS, enfim, a todo momento se é bombardeado: "professor cadê o link", "professor cadê o texto de não sei o quê", "professor não estou conseguindo entrar", "professor não estou conseguindo pagar o boleto". Então, penso, Elaine, que toda essa mediação da tecnologia da informação e comunicação entrou nesse movimento que o Han identificava como essa máquina do desempenho, levando isso ao extremo porque o desempenho para nós passou a estar quase que onipresente.

Gilles Lipovestsky (2007) também tem essa ideia do desempenho na sociedade de consumo, do hiperconsumismo, do paradoxo da felicidade. Ele vai falar também dessa questão do desempenho, mas é um autor que tem uma visão muito realista da realidade em que nos situamos. Passou de uma franca defesa ao individualismo a uma crítica severa do mesmo. Porque no início da sua reflexão, ele pensava o individualismo. Por outro lado, seus últimos escritos são mais contra essa postura muito individualista que rompe os vínculos e ousa e projeta a instrumentalização do outro para seu próprio benefício.

Então, para voltar a essa questão do desempenho, para Gilles Lipovetsky (2007), nessa sociedade do hiperconsumismo, tem que ter esse desempenho, o consumo a todo custo e em todas as áreas, inclusive no que concerne às relações afetivas amorosas e até sexuais, tem que ter o desempenho máximo. Chega ao ponto de tocar a intimidade conjugal; temos que ter o desempenho máximo sexual, embora na realidade do dia a dia não é bem assim, devido a uma série de circunstâncias. Não é que não haja necessidade de buscar o prazer sexual, mas é fato também que há dias em que se está cansado, há dias em que se está de mau humor e isso tem uma implicação nas relações íntimas. Então, a maximização do desempenho em todos as áreas toca também uma questão de consumo.

Elaine - Minha irmã esteve na Coréia do Sul e detestou porque desprezavam totalmente o tradicional numa busca frenética pela modernidade e consumo.

Rafael - Elaine falou da irmã, que foi à Coreia do Sul, mas isso é típico na Ásia, onde o consumismo entrou como um rolo compressor. Eu fiquei chocado com os jovens chineses que acolhi na Bélgica. Estudei no Rio, na Filosofia em 97/98, com dois futuros padres chineses, atualmente padres e, quando fui para a Europa estudar, eles mandavam os sobrinhos, os parentes chineses que iam estudar na Europa, em grandes universidades. Mas eu ficava impressionado! Não via mais neles a sua cultura; era a cultura consumista! Um ritmo frenético assim de vida, com aparelhos de última geração, com roupas de marca, e o visual, e pensava: "Poxa, não falam nada da realidade chinesa, é só a realidade do consumo."

Essa questão do desempenho é um tema muito importante no pensamento do Han, e está ligado ao excesso de positividade, no sentido de produzir um bom resultado. Tem que ser positivo e tudo tem que correr bem, não pode sair nada do esquema... E isso causa uma pressão em cima de nós muito grande. Temos que produzir; tem que ser bem feito o que se faz; tem que funcionar; tem que dar resultado. E aí se entra de fato em um momento em que não se aguenta mais. Foi esse 
esgotamento que se viu no final do ano passado. Tudo bem, temos que trabalhar durante a pandemia, vamos lá, vamos fazer algo. Mas todo mundo acaba se sentindo esgotado.

Giovana - Tem uma coisa que me chamou muito a atenção no documentário ${ }^{1}$ que vimos antes, quando ele diz: "Mudou-se para essa nova realidade do 'você deve' para 'você pode', dizendo ser essa condição uma autoexploração." Eu também sou professora, então nosso trabalho termina, muitas vezes, se estendendo até à madrugada, com as pessoas trocando mensagens, de professor para professor e com alunos também. Essa autoexploração é comentada por Han como uma falsa liberdade, de que você pode fazer as coisas, que pode decidir, mas, na realidade, estamos nos colocando em uma situação de esgotamento. "Não, eu decidi que eu não vou mais receber mensagens por e-mails ou WhatsApp, e que às nove horas eu vou bloquear". O Han remete a outro livro dele - A Sociedade da Transparência (Han, 2016) - onde descreve o papel das redes sociais em fazer com que as pessoas se exponham e, na realidade, elas estão sendo vigiadas sem que se deem conta do impacto da sua própria exposição. Após ter assistido esse longo documentário, eu falei: "Meu Deus do céu, o pior que é mesmo! Será que eu também não estou nessa exploração de mim mesma? De você estar colocando no Instagram e em tudo?". Eu achei, assim, bastante interessante, porque somos "culpados" de como estamos nos sentindo, esgotados. Estamos fazendo isso. É aquela questão da autoexploração.

Rafael - Essa questão da Sociedade de Transparência tem um pouco a ver também com aquilo que o Guy Debord (1997) tinha falado sobre a sociedade do espetáculo, ou seja, a exposição ao máximo que acaba virando também uma espécie de entretenimento (Han, 2019). E nós queremos estar nisso também porque há uma necessidade quase que afetiva de ser visto, ser reconhecido.

Gilmara - Pensando no campo da saúde, percebe-se muito a cobrança, cada vez mais intensa das muitas creditações para buscar a excelência do serviço. Há muitos marcadores de qualidade da assistência, e vem um público de fora avaliar a instituição, perceber como é que têm sido os processos os quais geram uma melhor assistência àquele paciente, naquela família. E todos os colaboradores, fisioterapeutas, enfermeiros, médicos, são atravessados por essa cobrança, a cobrança do indicador de desempenho, porque a instituição deseja. A psicologia é um núcleo dentro da instituição privada que também é cobrada em seus indicadores. Na pandemia, esse desempenho foi cobrado em chamadas de vídeos para as famílias, atendimentos por chamadas telefônicas, entre outros. É muito difícil você estar num espaço onde é cobrado pelo desempenho (Filho, Rosa, \& Marchiori, 2020), que é um desempenho que se assimila a um processo que a industrialização trouxe, que se deve produzir se aproximando da máquina. Na psicologia, nosso trabalho é, assim, como de fisioterapeuta, artesanal. Não dá para um trabalho artesanal se aproximar de um trabalho mecanicista. $\mathrm{O}$ trabalho da psicologia envolve conferências familiares, por vezes longas, atendimentos mais demorados, sinalizando a singularidade destes. Por justamente ser um trabalho artesanal é importante que não se torne um trabalho isolado. A instituição cobra indicadores. Aí entram questões que também são éticas e outras questões objetivas que nos envolvem. Há necessidade de se manter a postura de que nosso trabalho é cuidadoso, requer escuta, comunicação atenta, construção do vínculo, e tudo isso leva tempo. Dentro de uma instituição, não se pode apenas trabalhar com psicoeducação, orientação de normas, de rotina... Fazer um acolhimento, breve que seja, demanda muito do profissional; para as coisas serem de verdade, para as coisas serem, na verdade, inteiras, elas precisam passar por tempo e dedicação. E se vê hoje o chamado Burnout que é a extensão disso. Vejo muitos profissionais que estão esgotados porque vêm se despersonalizando dentro de uma cultura que está querendo massificar. Esses dias, dando aula para meus alunos da pós na Santa Casa, utilizei a imagem de uma tela de Tarsila do Amaral, sobre os operários. O título inclusive é "Os Operários", e são todos ali iguaizinhos e juntinhos. É relativamente assim a realidade do trabalho industrial, cada um com sua forma de trabalhar, de ser, de viver, com seus talentos, dons. Contudo, muitas vezes necessitando abraçar todo o seu universo simbólico para

1 Documentário intitulado HAN, B.-C: Sociedade do cansaço. Disponível em: https://www.youtube.com/watch?v=VbPv H515KoY\&feature=youtu.be, dado como leitura prévia à aula. 
guardar para si e poder estar ali no mundo a serviço de outros, com outros. Então, é muito excesso de cobrança, de buscar essa normatividade, buscar esse desempenho de excelência, atender a todos os marcadores sociais, de uma série de coisas, e as pessoas no trabalho estão se despersonalizando. A despersonalização, com o excesso da cobrança, com a exaustão, de fato está levando ao Burnout.

Ana Cristina - Usando como base as falas até então, acrescentando que trabalho como psicóloga clínica, neste lugar percebo a ampliação direta de diversas sintomatologias. Percebo que no decorrer da pandemia as crises de ansiedade, depressão, pânico, Burnout, se ampliaram muito, emergiram com muito mais potência. Fazendo um paralelo entre o texto e o que vivencio diariamente, a fala do "cansaço", a necessidade de "dar conta de tudo", ignorando muitas vezes as necessidades físicas ou psíquicas, tem impulsionado as pessoas, cada vez de forma mais frequente, à utilização da medicalização.

Elaine - Meu marido era jornalista. Escrevia na máquina de escrever. Aí chegou o computador na imprensa e, com o computador e a informática, veio uma grande mudança no jornalismo. Ele chegou à conclusão de que ele tinha virado um "dinossauro", um ser em extinção, porque ele era um escritor e achava que aquilo que ele era e sabia tinha se tornado desnecessário, obsoleto. Por que eu estou contando isso? Por que penso, apesar de tudo que estamos falando, que vai vir uma Revolução Cultural, que é a cultura que vai ser transformada pelos jovens, não por nós, pelos jovens que estão vivendo essa situação de uma maneira que não se consegue sequer entender? Por quê? Porque, por exemplo, hoje, no jornalismo, há muito interesse no jornalismo de pessoas como ele, os articulistas, os críticos, o jornalismo investigativo. Para poder competir com os outros mídia tem de ter um diferencial na escrita e na capacidade discursiva.

Flávia - Gostaria de ressaltar um aspecto da estética do documentário Sociedade do cansaço: Byung-Chul Han em Seul/Berlin (2015) dirigido por Isabella Gresser. O documentário se inicia em Berlin e é filmado em preto e branco e o ritmo das imagens e das informações é lento. Han vive na Alemanha há mais de trinta anos e, na primeira parte do documentário, conta-nos sua chegada a esse país para estudar filosofia e literatura na Universidade de Friburgo. O documentário faz um passeio pelos lugares frequentados pelo filosofo em Berlin, cidade onde reside e atua como professor de filosofia. O ritmo é lento e nostálgico. Este ritmo, que me parece intencional, faz o espectador desacelerar e refletir sobre uma enxurrada de informações que nos invadem diariamente. Senti vontade de adiantar o documentário e chegar logo ao conceito de sociedade do cansaço. Esse desejo de ir direto ao ponto, consumir informação em um modo automático é um dos sintomas do cansaço e da exaustão que vivemos. O ritmo muda quando Han chega a Seul. A partir desse ponto, o filósofo utiliza a sociedade coreana como exemplo emblemático da sociedade do cansaço. A Coreia passou rapidamente de um país agrícola para uma nação industrializada. Para Han, a síndrome do esgotamento é global, mas em algumas sociedades como a Coreia é mais grave. A sociedade não é mais controlada por ordens ou proibições, mas por uma ideia de liberdade, e marcada pela crença do "sim, nós podemos". O controle agora é interno, e, quando o sujeito não consegue alcançar o sucesso se sente culpado e responsável pelo fracasso. Há uma suposição de liberdade, mas, na verdade, somos explorados voluntariamente até entrarmos em colapso, que se traduz em adoecimento psíquico como o Burnout e a depressão.

Rafael - Pegando aqui o gancho com o que a Flávia diz, no meu ponto de vista, na minha ignorância em termos de psicologia, quando se fala de depressão e de Burnout, também da crise de ansiedade que está um pouco ligada a isso, obviamente, a cidade está muito ligada à depressão e ao Burnout, mas penso que a parte da ansiedade está ligada a tudo isso que ele está falando. No meu ponto de vista, na minha análise subjetiva que faço olhando pra mim mesmo, para pegar o "Conhece-te a ti mesmo" em primeiro lugar, desde os antigos filósofos, acredito que justamente a experiência da depressão e do Burnout tem muito a ver conosco situados no tempo e no espaço. Como a subjetividade, como nós, na nossa subjetividade nós situamos no tempo e no espaço, e como nós experimentamos essa relação, para falar também de vínculo, e de relação com o tempo e o espaço. É fundamental, para ir ainda mais além, não só como nós situamos o tempo e o espaço, mas como os preenchemos, como habitamos o tempo e o espaço. Penso que é uma questão muito ligada ao que concerne ao desempenho, o 
ritmo frenético que se instaura. É que nós acabamos não percebendo muito bem o tempo e o espaço no qual nos situamos. Obviamente, como dizia um velho professor de filosofia, o tempo é uma coisa que nos toca e foge rapidamente. Parece muito interessante dizer assim. O tempo é algo que nos toca e foge, não se deixa pegar. Obviamente que existe, como posso dizer, essa incapacidade de dominar o tempo é até mesmo os espaços, mas existe, sim, um modo como nós situamos e como nós somos afetados, como nós nos relacionamos com o tempo e o espaço, que muitas vezes, também são categorias abstratas. Nós traduzimos isso, nós medimos, mas ao mesmo tempo nós extrapolamos as categorias, as mensurações do tempo e do espaço. Algo que extrapola um pouco as medidas do tempo e do espaço. Nós tendemos a extrapolar isso, até na questão do espaço em relação às fronteiras tendemos a fazer isso também. Senão viajando, mas pelas informações que nos chegam, por alguma coisa que nos leva, transportando em fronteiras. Então, penso que há alguma coisa muito importante na atualidade no que concerne à depressão, Burnout, a ansiedade, em relação ao modo como a pessoa se situa subjetivamente no que diz respeito à experiência do tempo e do espaço.

Jeane - Foi bom pra mim, sabe por quê? Foi um treino para escutar, não falar, ouvir o outro e não falar. Preciso fazer isto, talvez. Para quem é psicólogo, isso é mais fácil. Talvez eu, por ter estado sempre em sala de aula, mesmo na condição de gestora, está-se sempre falando. Então, foi um exercício para mim, até para ter paciência com essa questão da internet; para lidar com calma. Eu pago para ouvir, né. Penso que já comentei aqui: sou deficiente auditiva, aí eu pago para ouvir; eu preciso ouvir. Mas eu lembrei de um poema de Drummond (2015) que, no livro Corpo, Eu etiqueta, ele afirma justamente o processo de coisificação. Por seguir os modismos, o ser humano perde a identidade, as idiossincrasias. Perde tudo e se coisifica.

Elaine - Gosto muito do que Han fala sobre cansaço solitário. Para ele, o cansaço da sociedade no desempenho é um cansaço solitário que atua individualizando e isolando (p 71). Handke (citado por Han, 2017) chama de cansaço dividido em dois: ambos se afastam, distantes um do outro, cada um em seu cansaço extenuado. Então, não mais o nosso, apenas o meu cansaço aqui e o teu lá. E o nosso, onde é que fica? Para Han (2017), este seria o espaço para o outro. Esse cansaço dividido em dois atinge as pessoas com incapacidade de ver e falar. São violências que destroem qualquer comunidade, qualquer elemento comum, qualquer proximidade, inclusive a linguagem (p. 72). Esse Handke é um prêmio Nobel, ele é alemão, mas se diferencia dos escritores alemães do pós-guerra e pós nazismo, porque não entra na culpa do nazismo, mas na questão da subjetividade.

Rafael - Só queria trazer talvez mais um elemento que concerne muito a nós. Sobretudo quando pensamos a temática do vínculo, estamos pensando neste espaço relacional, ou seja, um espaço relacional que segundo alguns autores não é qualquer coisa, não é algo abstrato. Então esse cansaço dividido em dois significa fragmentação, não há espaço relacional, não é colocado em comum. Porque o espaço relacional é o espaço onde colocamos a vida em comum. É onde nós partilhamos a vida, onde nós saímos um pouco da individualidade. É verdade, criamos nosso espaço privado pessoal, e isso também é necessário. Preciso deixar claro que isso não é tão assim mecânico e compartimentado, mas, em termos de imagem, sai-se um pouco do "cômodo privado" para entrar no espaço comum. Ali é o espaço em que se compartilha com os outros a vida e aquilo que experimentamos. Nisso, obviamente que a linguagem é um dado existencial do ser humano, extremamente relacional. Não só com o próprio ser humano, mas com toda a realidade. Assim, a linguagem é própria do espaço relacional e a vida em comum. Não se pode perder isso, de fato. Até me fazia a seguinte reflexão: Elaine falava agora há pouco dos benefícios que nós podemos encontrar por meio do uso das Tecnologias de Informação e Comunicação e que, de fato, existem benefícios. Estão sendo publicadas cada vez mais pesquisas mostrando também os malefícios em relação ao uso excessivo das Tecnologias da Informação e Comunicação já pelas crianças no que concerne à cognição e, consequentemente, à questão da fala (Johnson, 2020; Neophytou \& Manwell \& Eikelboom, 2019). Estava me fazendo a seguinte observação. Talvez seja uma impressão só minha, mas estou tendo a seguinte impressão: estou percebendo que o uso, o fato de se estar muito, como eu dizia, no modo de processamento de leitura na tela, trata-se de um modo de processamento neural, enquanto no papel, é outro. 
Até se consegue perceber que na tela não se identificam certos erros, enquanto no papel, são identificados. Tem-se outra percepção. Há um modo de processamento que alguns apontam que não é a mesma coisa. Já dizia um grande amigo português, no início dos anos 2000, quando começamos a usar mais as telas: é importante variar de vez enquanto e não ficar somente na tela do computador. É claro, há também uma questão de dificuldade de leitura que nós já enfrentamos há muito tempo.

Pergunto-me se não está havendo um impacto na questão da linguagem pelo fato de passarmos muito tempo numa leitura que muitas vezes é subjetiva, silenciosa, melhor dizendo, na tela. E, quando ouvimos alguns jovens lendo, há um atropelo, uma dificuldade na linguagem, sabendo que aquele jovem não tem dificuldade com a compreensão do texto. Estou fazendo aqui uma hipótese que parte um pouco das minhas impressões, observações quanto à leitura. Refiro-me à leitura em voz alta. Percebi que há uma dificuldade em relação à leitura, o que no meu ponto de vista não concerne somente a uma dificuldade propriamente de conhecimento da língua portuguesa, mas, no meu ponto de vista, existe uma dificuldade que está sendo acrescentada. Daí que talvez advenham essas dificuldades que algumas pesquisas estão apontando. Trata-se de uma diminuição, segundo algumas pesquisas, do QI dessa geração atual muito imersa a todo o momento mundo nas Tecnologias de Informação e Comunicação, diferente de uma geração anterior que estava um pouco mais meio a meio. Vivia tendo contato com a Tecnologia de Comunicação e Informação, porém ainda com leitura de livros etc.

Queria ainda falar sobre a questão de o espaço do vínculo ser um espaço relacional como possibilitação do vínculo, como o húmus de uma terra fértil. Para que o vínculo possa ser um espaço relacional, esse húmus deve gerar comprometimento no espaço comum. Outro ponto é que Han (2017) vai na linha de um quase comunitarismo, a tal ponto, não sei se Elaine se recorda, que ele tende até a diminuir um pouco ou totalmente o papel da família nesse contexto de socialização. Ele foca muito na vida em comunidade como sociedade. Ele aposta muito nisso e menos na família.

Elaine - Destruindo o vínculo, destrói e domina, controla. Está mencionando o mecanismo de controle social, que é o problema da emergência atual das ditaduras. Essa é outra leitura que se segue a essa violência que acaba com um elemento comum, porque a pessoa fica facilmente controlável, cada um na sua toca, na sua concha. Han, depois do cansaço solitário, menciona o cansaço falaz, o cansaço que fala e que vê, que reconcilia. Para Han, "o cansaço enquanto mais ou menos abre um entre, na medida em que afrouxa as presilhas do meu eu" (2017, p. 72). O Brasil é uma sociedade mais ou menos. Não somos muito cartesianos por causa da influência indígena, afro e também dos portugueses. Então, no Brasil, trabalha-se numa área de graduação enorme entre o branco e o preto, muitos cinzas, e se transita entre essas áreas. Essas outras sociedades não fazem isso. São intelectualmente, rígidas e, para nós, há mestiçagem cognitiva. É muito interessante Han colocar o mais ou menos porque ele veio da Coréia para a Alemanha. Confrontou essas culturas dentro dele, percebeu as diferenças. O Brasil permite um entre, tanto que o Brasil virou um modelo de modo de ser no futuro (Laplantine, \& Nouss, 1997) justamente pelo trânsito que se faz aqui, ou fazia. $O$ trânsito entre, o entre, estou aqui, estou ali; não entro em contradição necessariamente.

No cansaço falaz, "Eu próprio sou o outro e o outro torna-se igualmente eu" (p. 77). Denomina este como um espaço de amizade, com in- diferença porque não tem diferença entre as pessoas, onde ninguém ou nada domina. Ao tornar-se menos, o "eu" desloca o peso do ser do eu para o mundo. O brasileiro está perdendo uma espécie de abertura permanente para o colonizador, o Outro. Essa é a história do Brasil: tudo o que vem de fora, você devora e passa a ser você. A hipótese antropofágica é a metáfora do Brasil: na antropofagia você não tem o domínio, você tem o domínio ao devorar e, assim, passa a ser teu, mas não é um tornar-se menos. (Ribeiro, 2015).

O texto me fez refletir o tipo de vínculo que vem pela amizade como modelo de relacionamento. A philia é uma das grandes formas de amor, que é a amizade. Nas amizades é bom quando ninguém domina ou tem predomínio, porque, em princípio, não precisaria ter nada a ver com poder. Han (2017, p. 76) enfatiza que há um deslocamento do peso do ser do eu para o mundo. Vocês, comentando o filme, fizeram-me pensar que a lentidão é proposital; é para se deslocar de si para o mundo, no ritmo de que você olha e deixa o que está fora entrar em você. Segundo ele, é um cansaço que confia no mundo, 
possibilita um demorar-se, enquanto o cansaço do Eu, o cansaço solitário, é um cansaço sem mundo, destruidor de mundo.

Rafael - Digamos assim, ele passa para uma visão da experiência do próprio Ser da Pessoa em relação a uma realidade e aos outros também. Eu estava aqui pensando a Pessoa em relação à realidade, aos outros também. Estava aqui me questionando porque ele volta a essa questão da dualidade destruída. Quer dizer, o que ele está propondo aqui é que esse ser se reconstitua, possa retomar esse espaço comum. Quando se fala justamente da amizade, a ideia é essa, retomar propondo que esse cansaço não seja também vivido de fato de modo isolado, que se abra, menos focado em si mesmo e que haja aí uma abertura para a realidade. Que, claro, passa pela ação com o outro, com os outros.

Elaine - Han (2017) propõe o cansaço fundamental como antídoto para a sociedade do desempenho porque ele inspira, faz surgir o espírito. Diz: (p. 73): "A inspiração do cansaço" equipara-se ao não fazer, dizendo menos do que se deve fazer e mais do que se pode deixar de lado, um não fazer sereno". Aponta que este cansaço falaz seria uma forma de salvação, de rejuvenescimento, trazendo de volta a admiração. Admiração é para-mirar; e admirar é um dos sentimentos mais importantes que existem nos vínculos. Você admirar o outro, sem colocar no pedestal. Não precisa idolatrar, mas admirar. Rafael, esse cansaço inspira e faz surgir o espírito, isso aí é tua área.

Rafael - É um pouco aquilo que a Jeane recordou na última aula, porque a palavra alma, remete a animus. Então, um pouco na mesma linha, inspirar é dar espirito, dar ânimo! Na verdade, dar vitalidade, não é? Ele falava dessa vitalidade anteriormente, lembra? Ele dizia que essa vitalidade foi um pouco desconfigurada com essa coisa de mais vida, mais doping, com essa energia dos energéticos que estão na moda; tomar muito energético para ter supostamente "mais vitalidade", que não é a vitalidade real que ele está apontando aqui. Essa vitalidade tem que brotar justamente de algo mais profundo, que não é algo que deixa o eu bombardear o corpo por agentes biológicos, mas um corpo vívido plenamente, com todo espírito que o move. É isso que ele quer dizer sobre essa inspiração do cansaço. Interessante isso, né?

Rafael - É muito interessante, porque justamente o que ele propõe não é um estado de onde todos os sentidos estariam extenuados, quer dizer, que os sentidos estariam esgotados, mas que permite o acesso a uma atenção às formas longas e lentas, que escapam à hiperatenção curta e rápida, que é desse mundo frenético, dessa economia da eficácia, da sociedade do desempenho que ele está trazendo para nós. Essa sociedade do desempenho perde essa visão das formas longas e lentas, dentre elas uma verdadeira admiração: deixar-se tocar pelas coisas e admirar. Aí eu faço um paralelo com o tema da contemplação. O admirar tem essa porta de entrada até a contemplação. Você para e, de repente - para pegar um pouco dos sentimentos que você falou, pois é bem afetivo também - se é tocado por uma coisa. Você vê uma bela flor, vê um quadro que te inspira, ou a própria pessoa. Quero voltar rapidamente a "esse não fazer", dizendo menos do que se deve fazer e mais do que se pode deixar de lado.

Sandra - Professor, eu posso fazer um comentário para não perder o que falou anteriormente? Quando diz assim: a percepção das pequenas coisas, como olhar a uma flor. Penso que nesse momento de pandemia começamos ou voltamos a ter esse olhar voltado as essas coisas pequenas. Talvez por estarmos muito tempo em casa em isolamento, buscamos dar um sentido a todos os momentos, quer seja de cuidado com as coisas do lar quer de contemplação das pequenas coisas, como por exemplo, olhar uma planta, uma flor, os pássaros que passam pela nossa janela, etc. Devido ao isolamento social senti a necessidade de voltar a ter um contato com a natureza e imaginei como fazer isso se moro em apartamento pequeno e sem varanda. Então coloquei em minha janela plantinhas, um alimentador com água para atrair passarinhos e poder contemplar os pequenos detalhes dos mesmos. Deste modo, encontrei uma forma para desacelerar a vida externa. Isso fez com que percebêssemos a delicadeza dessas vidas naturais, que com o corre-corre deixamos passar despercebidos. Por ser do interior, sinto essa necessidade, além de já ter trabalhado muito com educação ambiental, com a sustentabilidade. Giovana, se eu não me engano, lá no comecinho da aula, comentou que tem muitas plantas e animais ao redor de sua casa e falou dessa importância. Acredito que nós estamos contemplando mais, pela necessidade de preenchimento de um vazio que ficou. Sair 
dessa vida mecânica. Ao acordar, fico olhando para minha rosa do deserto, dando bom dia e agradecendo a Deus. Isso me acalenta! Acredito que esse momento nos chama também para isso, para que percebamos as pequenas coisas, quer seja no setor pessoal e quer interpessoal, a importância nesse momento da presença da natureza, o que ela nos traz. Lembro que no início da pandemia ninguém estava saindo de jeito nenhum. Estava todo mundo em pânico. Moro perto da praia, na orla. Passava ali e via o quanto esse mar estava lindo e cristalino. E eu comentava: isso é coisa de Deus! Para percebermos o quanto danificamos a natureza hoje. Fui trazida de volta. Porque quando eu ainda residia no interior, morava em casa enorme, muito espaço externo e não valorizava. Hoje estou desejosa por uma área e não tenho mais. Então, é isso, penso que é um chamado também para que, com a sensibilidade que estamos, agradecer a Deus, dar valor a tudo quem tem vida. Obrigada pela oportunidade!

Giovana - Do que Sandra estava falando, consegui fazer uma troca muito positiva das tarefas que eu fazia antes. Com a pandemia, fiquei muito agitada dentro de casa, com muito trabalho remoto, apesar de eu ainda sair para atender. Busquei fazer coisas que eu sempre gostei de fazer e que não tinha tempo como cozinhar, cuidar das plantas. Agora tenho pássaros que vêm comer na minha casa e fazem ninhos nas árvores, além de uma família de mais ou menos quinze micos que aparecem toda tarde para comer bananas.

Cuidar de tudo isso é muito prazeroso e pode nos dar a falsa impressão de que não cansa, mas cansa, porque dá muito trabalho para fazer. Moro numa cidade onde as construções são mais de tipo casas. Aqui a maioria das pessoas com quem convivo trabalha com jardim, caminha no condomínio. Aí, não se engane: às vezes uma situação muito prazerosa também pode estar te sobrecarregando. Você também fica sobrecarregado com isso. Sandra estava falando que é um prazer você abrir sua janela, ver sua rosa do deserto florir, mas você tem que ter o cuidado diário. Então, se você soma esses pequenos afazeres, incorporando coisas que te dão prazer, isso vai se somando às suas outras tarefas. Ou seja, temos que tomar cuidado. Aí meu marido diz: E eu? Que migalha vai sobrar para mim no final do dia? Então, tenho que parar com a compulsividade de comprar mais plantas, de querer cuidar dos passarinhos e micos que aparecem, para diminuir meu cansaço no final do dia e sobrar um pouco tempo para a família.

Elaine - Seu pensamento pode ser sintetizado dizendo que eu não estaria cansada de ti, mas cansada para ti. Se o cansaço do esgotamento nos incapacita a fazer qualquer coisa, o cansaço que inspira é um cansaço de potência negativa, a saber, um não-para. Dá abertura para o outro. No fundo, é isso: o eu para de existir o tempo todo e deixa o outro existir. Esse cansaço cria uma amizade profunda e torna palpável uma comunidade que não precisa de pertença, nem de parentesco. Então veja, Rafael, Han não valoriza a família mesmo. Está pensando numa sociedade universal ideologicamente, dentro dessa perspectiva internacional.

A seguir, Han menciona o Shabat, o dia do descanso dos judeus:

Shabat originalmente significa parar, é um dia do não-para, um dia que está livre de todo para-isso. Trata-se de um tempo intermédio, dia do descanso de Deus, o sétimo dia, um dia sagrado, que é o dia do não-para, um dia no qual seria possível o uso do inútil. O tempo intermédio é um tempo sem trabalho, lúdico, de paz (shalom). É um tempo da in-diferença como amizade. (Han, 2017, p. 76).

O shabat para os judeus começa em toda sexta-feira. Começa na hora em que surge a primeira estrela. Assim é a religião. No mundo todo, na hora em que surge a primeira estrela, tem que acender uma vela, reza-se sobre a vela, e quem faz essas rezas são as mulheres. E, daí, durante 24 horas, não se pode fazer nada. Para o judaísmo tradicional, para seguir o shabat não pode acender fogo - porque antigamente fazer fogo dava trabalho - então existe uma tecnologia de tal maneira que tudo funciona sem ninguém fazer nada. Levando tudo isso radicalmente, realmente é "parar", é o dia de comemorar, viver em família e de rezar. É um dia de muita alegria também e não pode ter comemoração de luto. Orientei dois adventistas e os adventistas são muito parecidos com os judeus. Eles respeitam também o shabat porque seguem a Bíblia estritamente.

Jeane - Os adventistas seguem o shabat. Não abrem o comércio, não trabalham. Não fazem nada, só o culto. Eles têm 
o culto no sábado. Assim como os judeus, eles não comem carne de porco e também não comem camarão. Acham que é pecado mesmo. Param mesmo. Começam sexta às $5 \mathrm{~h}$ da tarde e só voltam no sábado às $5 \mathrm{~h}$ da tarde. Inclusive, antes, quando tinha ENEM no sábado e no domingo, eles tinham que chegar no local da prova, ficarem lá esperando o horário com o fiscal sem abrir a prova e a prova para eles começava às 5 horas. Às 5 horas eles começavam e terminavam tarde da noite. Por isso, inclusive, o ENEM saiu do sábado. Agora são dois domingos. Porque era custoso, inclusive.

Elaine - Eu acho interessante o Han trazer o exemplo do shabat porque é a pessoa fazer uma vida num contrafluxo. No entanto, dentro desse contexto que ele traz, fica cheio de significado.

Jeane: E tem uma coisa assim bem legalista. É uma lei. É normativo.

Rafael - Eu queria sair um pouco do discurso das práticas, que são bem complexas e têm vários elementos a serem considerados. Estou tentando entender um pouco mais o Han no que diz respeito a essa noção do shabat, do repouso, do parar. É porque, de fato, vai no sentido do que ele está afirmando, contrapondo-se a essa sociedade da positividade, do desempenho, da maximização da positividade, que é fruto desse desempenho. Na verdade, positividade ligada ao desempenho e ao fazer. E ele traz um exemplo prático que de fato é um exemplo forte, porque evocamos as tradições do judaísmo e dos adventistas.

Rafael - Mas o que eu acho intrigante é que, de fato, a noção de shabat é essa parada total, isso eu quero dizer. É como se fosse um descanso, um repouso total de todas as coisas e o Han vê isso como algo de negatividade, mas que tem sua positividade. É esse não-para. É não fazer para alguma coisa. Não é um não-parar: não parar de fazer alguma coisa. É um não para alguma coisa. Ou seja, dizer não, não significa simplesmente fazer menos; é deixar de fazer. E o shabat traz isso: não é deixar de fazer menos, é deixar de fazer. Estou tentando me colocar um pouco na cabeça do Han. Pensar isso, de fato, é muito interessante, porque esse deixar de fazer pra nós é o que dá uma possibilidade de abertura, um momento intermediário, como ele diz para se abrir um espaço e se abrir justamente para realizar essa função de incluir outros no nosso espaço e sermos incluídos no espaço do outro para criar esse campo de amizade. E nesse ponto, de fato, ele tem razão. Depois se poderia também questionar porque não traz espaços como o da família como sendo também espaços intermediários. Ali se poderia também fazer essa experiência. Mas aí também é outra questão. É o não fazer, mas o não fazer que traz uma possibilidade de abertura. É um não-para. Eu não faço porque isso me projeta, isso me abre. Não é uma inércia. É ocasião de se poder pensar o mundo, a sociedade de eficácia, de excesso de positividade. Pode-se pensar que não fazer as coisas parece certa inércia, mas não é. É um não que tem um potencial, que inspira, como ele diz, que traz o espírito que potencializa.

Jeane - Não seria o ócio produtivo que está lá em Aristóteles (1985)?

Rafael - Aliás, você toca num ponto interessante. Aristóteles é um autor que de vez em quando volta. Apesar de eu pensar que Han é platônico em relação à família. Totalmente platônico, eu diria, e menos aristotélico. Mas você tem razão. Porque, de fato, não se inventa nada com a "varinha mágica". Acaba se fazendo uma composição. Vai-se remodelando, trazendo com ares novos. As coisas não caiem do céu assim de qualquer jeito. Então, é isso, Jeane, tem um pouco dessa ideia de Aristóteles, sim. É importante pensar sobre isso. Em outras passagens ele se refere a Aristóteles no que concerne a essa temática, em particular em Aroma do tempo: um ensaio filosófico sobre a arte da demora (2016).

Elaine - Mas, Rafael, eu queria que você falasse mais um pouquinho sobre Platão e Aristóteles porque eu não sei essa diferença em relação à família?

Rafael - Sobre a família, é uma diferença bem básica. Até posso dizer que as duas linhas perpassam dois milênios de história no que se refere à visão sobre a família. Aristóteles tem uma visão da família como de fato sendo uma relação própria do ser humano e, por isso mesmo, algo que é necessário para a sociedade, o início de experiências básicas da vida em sociedade. Já Platão (Donati, 2001) não tem essa percepção de que os vínculos familiares sejam pertinentes para a vida em sociedade, até porque ele tem uma concepção de sociedade, assumida pelo Estado ideal, que é diferente daquela de Aristóteles. Platão tende a valorizar menos o papel, a existência da família na sociedade, as relações familiares para os próprios indivíduos, 
enquanto para Aristóteles é ao contrário: ele tende a valorizar a família, o seu papel em sociedade para os próprios indivíduos. E, ao longo dos séculos, oscila-se em relação a uma ou outra dessas duas abordagens. Nesse ponto, o Han vai divergir do sentido de Aristóteles, e nesse ponto ele é bem foucaultiano. Foucault, em debate com Chomsky (2005) também demonstra uma tendência a não ver a importância da família. Ele tende até a considerar que a família seja um empecilho para aquisição dos direitos individuais e democráticos, visando ao crescimento de aquisição de direitos dos sujeitos em sociedade.

Há também Cícero (1913) que, baseando-se em certa associação com o pensamento de Aristóteles, afirma que a família é seminário das coisas públicas, o que não é o caso pra Platão. Interessante perceber os distintos posicionamentos em relação às relações familiares. Quando se vai para o surgimento da sociologia, com Comte, que tendia a valorizar a família na sociedade, e Marx e Engels (1984) a lhe oferecerem oposição.

Giovana - Qual a influência da escola de Frankfurt e o que se esperava desta linha marxista?

Elaine - A Escola de Frankfurt é fundamental para a estruturação do pensamento em várias áreas e, sem dúvida, na área de onde eu venho que é a psicologia social. E a discussão que estamos tendo hoje está bem dentro desta tua pergunta. Isto porque o Han é a favor de um universalismo que era defendido por todas essas correntes que vêm de uma forte influência marxista. Ninguém estava defendendo família a esta altura. A família era considerada um mundo fechado, muito tradicionalista, que se opunha às transformações desejadas por essas correntes. Todas essas pessoas sonharam com a mudança do mundo - essa visão acabou sendo derrotada - e para isto teria de mudar a família, aquele tradicionalismo que existia nas estruturas familiares. Você pensa no patriarcalismo, por exemplo, na relação entre o que se chama de gênero. Han claramente está nesta linha ao lado dos universalistas, tanto que fala da sociedade do futuro. Sou de uma geração que cresceu nesta crítica à família. Roudinesco (2003) é da mesma geração do que eu e, no entanto, diz que a única instituição que permaneceu é a família. Família quem é? Quem cuida. Esta á a minha definição de família. Não é uma definição estrutural, é uma definição a partir da psicologia, dos relacionamentos, que é quem cuida. Cuidam uns dos outros; essa é a família. Por que se afirma isso? Por que se o bebezinho não tiver quem cuide dele, morre. É simples assim. Ele não sobrevive. Então, a visão na Psicologia acaba sendo hegemônica: não tem nenhuma teoria que diz que não tem de ter alguém que cuide. Cuidar mesmo. Não adianta vir de vez em quando alguém. A nossa aula hoje é sobre vínculo. O vínculo é construído a partir de um cuidado sistemático, é a função maternante, vamos dizer. Isso retoma a questão da família por meio do cuidado sistemático. Israel foi criado dentro de uma ideologia absolutamente socialista. Era uma ideologia comunitária como esta que o Han está propondo aqui. E o que fizeram com as crianças? Colocaram todas as crianças no kibutz em uma espécie de grande creche em que tinha um rodízio dos pais para cuidar delas. Os pais se revezavam nos cuidados de todas as crianças juntas. As crianças só iam dormir com os pais. Não deu certo! A experiência feita em Israel com o kibutz acabou comprovando que não dava certa esta criação coletivizada das crianças. As crianças queriam os seus pais. O vínculo tinha sido formado com aquele pai, aquela mãe. Esse ideário socialista quer o bem comum de todos e nós, agora, temos um reforço das unidades familiares como aquilo com o que se pode contar. Ainda mais na pandemia.

Jeane - Comecei pensando em Foucault por ele ser homossexual e o capitalismo levando à noção de família para procriar, com a norma heteronormativa muito forte. E o que Elaine falou me lembrou Platão. A questão da República e a hierarquia - tinham aqueles que iam ser soldados - onde o patamar máximo eram os filósofos; mulheres fora. Era democracia entre os homens livres. Mulher era para procriar. E a família se dissolve.

Rafael - Platão pensou em um Estado ideal, bem construído, projetado nessa República pensada por ele, em que o Estado que prevalece e não núcleos. Ora, pode-se dizer que a reprodução era apenas um meio para chegar a isso. Jeane, você tem razão, a experiência pessoal do Foucault também traz essa dificuldade de perceber o papel da família por conta da sua experiência da homossexualidade.

A Escola de Frankfurt, Giovana, estava em Frankfurt como um centro, fazendo convergir pensadores da filosofia e da 
sociologia. Grandes nomes como Adorno, Horkheimer, e o mais conhecido que ainda está por aí que é o Habermas. Não sei se há alguma figura feminina. Eles tendiam a resgatar grandes nomes da filosofia e refletir sobre seus sistemas de pensamento: o próprio Hegel, Marx, e outros também. Voltado para a família, quem é próximo à Escola de Frankfurt e que está também inclinado a questionar os vínculos familiares é o Marcuse (1982), que tem aquela produção sobre o eros: Eros e Civilização (1975).

Como disse Elaine, esse pessoal atravessou décadas, e houve certa modulação em relação aos laços familiares. Não se percebia a família como se percebe hoje. Isso, eu diria, vai de pari-passu com a visão do próprio indivíduo. Claro que nem todos se direcionaram para uma linha que voltava a ver a família como base da sociedade, com a sua importância, sobretudo no campo da experiência subjetiva. Como Elaine colocou, alguns tendiam a esse universalismo e às vezes focando na ideia do cuidado. Há pessoas que dizem que não há necessidade de família, basta um cuidador. O tema que o Han mencionou rapidamente - e que se poderia trabalhar - é que ele parece também colocar à margem o tema do pertencimento a uma família, que é um tema muito importante para nós, para a subjetivação. Pertencemos a uma história, a uma linhagem, e as narrativas trazem muito disso. Eu me narro numa história de pertencimento. Francesco Botturi (2009), filósofo italiano que venho trabalhando, retoma Paul Ricoeur (2004) para afirmar que, quando alguém me pergunta quem sou eu, a resposta é: tenho um nome, nasci numa família em tal lugar, tenho esses vínculos, sou dessa origem. Há uma história na qual somos encarnados. É concreto, há uma pertença encarnada na história. Não digo: sou uma pessoa composta por matéria e espírito com olhos de tal cor, cabelo de tal cor, tal altura. Não se responde assim. Respondo: sou filho de tal, atuo em tal área, etc. Essa é nossa identidade, nossa pertença, não são nossas características biológicas nem psicológicas. Isso para nós, no nosso Programa, passa pela família. Claro que se pode vislumbrar um futuro em que se faça toda reprodução em laboratório, em que nasçam crianças em maternidades e que sejam criadas por profissionais. Mas qual seria esse futuro? Não sei. Não sei também se vai existir. A família foi dada por morta (Cooper, 1986). No entanto, resistiu, continua vivendo, embora com suas diversas facetas. Vamos ter um futuro de indivíduos isolados, somente ligados por vínculos sociais? Penso ser difícil, mas pode ser que me engane.

\section{Considerações Finais}

O debate suscitado no decorrer de uma aula a partir da obra Sociedade do Cansaço de Byung-Chul Han, ampliando pela relação que professores e alunos realizaram em função de suas vivências e experiências pessoais e profissionais, num momento de crise mundial causada pela pandemia da Covid-19, revelou como uma disciplina pode se constituir em um espaço dialógico de troca de experiências e de conhecimentos de todos os envolvidos.

Salienta-se a compreensão de que as diferentes visões das relações familiares e seus desdobramentos na vida pessoal e social, ao longo dos séculos, partindo nomeadamente do pensamento de Aristóteles e de Platão, continuam se refletindo nas reflexões de um filósofo contemporâneo como Han.

Aprofundar a contribuição de Byung-Chul Han no que se refere à percepção dos comportamentos humanos e das relações socias hodiernas, para o pesquisador no campo das relações familiares, permite alagar a reflexão interdisciplinar por meio da Filosofia, confrontar suas reflexões com aquelas que vêm sendo elaboradas nesse campo e fomentar mais questionamentos, que demandam ulteriores pesquisas sobre o aporte do referido autor quando se trata de pensar a família e suas relações na atualidade.

\section{Referências}

Andrade, C. D. (2015). Corpo. Companhia das Letras.

Aristóteles. (1985) Política. Trad. Mário da Gama Cury. Editora Universidade de Brasília.

Botturi, F. (2009). La generazione del bene. Gratuità ed esperienza morale. Vita \& Pensiero. 
Research, Society and Development, v. 10, n. 7, e23810716436, 2021

(CC BY 4.0) | ISSN 2525-3409 | DOI: http://dx.doi.org/10.33448/rsd-v10i7.16436

Chomsky, N., \& Foucault, M. (2005). Della natura umana. Invariante biologica e potere politico. Derrive Approdi.

Cícero. (1913). De officis, livro I, XVII, 54. From the James Loeb Collection. With an English translation by Walter Miller. London: William Heinemann; New York: The MacMillan Co.

Cooper, D. (1986). A morte da família. Martins Fontes.

Debort, G. A. (1997). Sociedade do Espetáculo. Contraponto.

Donati, P. (2001). Manuale di sociologia della famiglia. Laterza.

Engels, F. (1984). A origem da família, da propriedade privada e do Estado. Civilização brasileira.

Filho, F. A., Rosa, P. O., \& Marchiori, G. R. S. (2020). From homo oeconomicus to the performance subject: the trajectory of the subject in the neoliberal model in the thoughts of Foucault and Byung-Chul Han. Research, Society and Development, 9(4), e130942964. https://doi.org/10.33448/rsd-v9i4.2964.

Foucault, M. (1979). Microfisica do poder. Edições Graal.

Gil, A. C. (2008). Métodos e técnicas de pesquisa social. Editora Atlas S. A.

Han, B.-C. (2016). Aroma do tempo: um ensaio filosófico sobre a arte da demora. Relógio d'Água.

Han, B.-C. (2019). Good Entertainment: A Deconstruction of the Western Passion Narrative. MIT Press.

Han, B-C. (2017). Sociedade do cansaço. Vozes.

Han, B.-C. (2016). Sociedade da transparência. Vozes.

Johnson, B. (2020). Impacts of Screen Media on Young Children. BMH Med. J.;7(4), 1-5.

Laplantine, F., \& Nouss, A. Le métissage. Flammarion, 1997.

Lipovetsky, G. (2007). A felicidade paradoxal. Ensaio sobre a sociedade do hiperconsumo. Companhia das Letras.

Marcuse, H. (1975). Eros e civilização. Uma interpretação filosófica do pensamento de Freud. Zahar Editores.

Marcuse, H. (1982). L'autorità e la famiglia. Einaudi.

Neophytou, E., Manwell, L. A., \& Eikelboom, R. (2019). Effects of Excessive Screen Time on Neurodevelopment,

Learning, Memory, Mental Health, and Neurodegeneration: a Scoping Review. International Journal of Mental Health and Addiction https://doi.org/10.1007/s11469-019-00182-2

Platão (2019). A República. (3a ed.), Editora: Edipro.

Ricoeur, P. (2004). Parcours de la reconnaissance: Trois études. Gallimard.

Ribeiro, D. (2015). O povo brasileiro. A formação e o sentido do Brasil. Global.

Roudinesco, E. (2003). A família em desordem. Zahar. 